\title{
The Urban Space Narrated By Guangzhou East Garden As A Fragment
}

\author{
Zheng Li \\ South China University of Technology \\ Guangzhou, China \\ lizheng@scut.edu.cn
}

\begin{abstract}
This paper elaborate on how Guangzhou East Garden describe the urban space as a fragment .In the paper, a deep analysis was devoted on analyze the relationship among the East Garden, river, streets and social space. Specific measurements were carried out on several historical maps. The conclusion is that the narrative reflect some space construction, the emotional tangle in the use of space, the different traction forces, the gravitational pull of city and society, and some historical relationship in structurally or non-structurally.
\end{abstract}

Keywords-the Guangzhou East Garden; the narrative for the city; social space

\section{INTRODUCTION}

City unlike buildings with text and decorative painting to help the narrative, never leave the narrative, when viewed from a larger picture. We cann't deny that the buildings, streets, cities and nature situation do not have the function of reflection of the social structure and the ideology of dominant government, and the pattern of urban planning, rural settlement in ancient world or now are the instances. This article elaborates on how Guangzhou East Garden describe the urban space as a fragment .The narrative reflect some space construction, the emotional tangle in the use of space, the different traction forces, the gravitational pull of city and society, and some historical relationship in structurally or non-structurally.

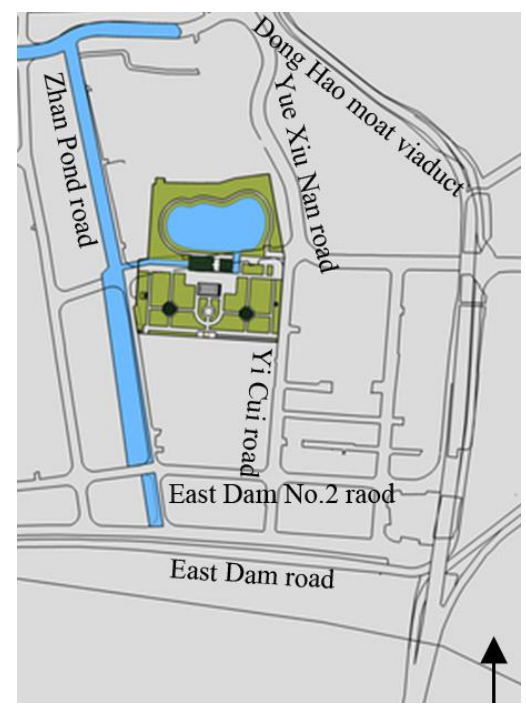

Figure 1. The reconstruction of East Garden superimposed on a current map of Guangzhou, edited by writer
Guangzhou East Garden is LI Zhun' office in temporary station who is the Prefect of the waterborne forces in Qing dynaity .It built in 1910, beside the Pearl river, outside the walls, at the southeast corner of the city. It's area is more than $24,000 \mathrm{~m}^{2}$.If the reconstruction of East Garden was superimposed on a current map of Guangzhou(Fig.1), we can see that it is east to Yue Xiu Nan road and Yi Cui road, west to East Garden road, north to the site of Chinese general labor union which was Huizhou guild hall, south to the south wall of Guangzhou labor union, strode over by East Garden road. Now, only the gate building (Fig.2) is the original one which is front entrance of East Garden, on the Yi Cui road. The top of gate building was decorated with plastered motifs of auspicious animals and patterns, which typified garden of that time. There had ever been a red and two-storey building (Fig.3) around arcade, which was burned by reactionary forces and rebuilt in 1984. North to the Red Building there had ever been a big pond, which was filled and used as a terminal in 1950'. These are the article which ever told about East garden. If the narrative stop from here, it is really boring. Actually when we read more deeply in the historical maps ,we can find out more the narrative this garden had told.

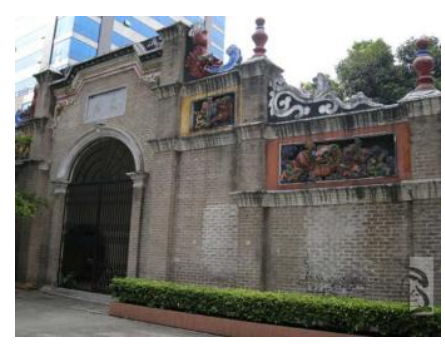

Figure 2. The gate building of East Garden

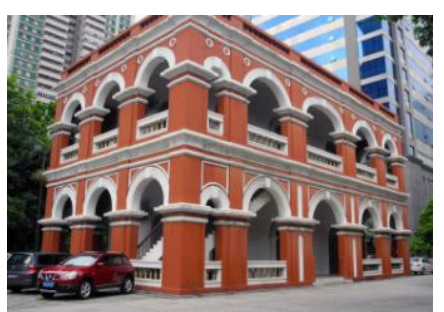

Figure 3. The Red Building of East Garden

We cut the East Garden part from several historical maps, as shown in the following pictures (Fig.4,from left to right, they are map for 1900, 1907, 1910, 1917, 1926, 1932, 1937, 
1949). The lower ones are superimposed by the space information including streets in 2012 and the East Garden. Then compared with the past and the present, with the literature, we find that the narrative about the urban space made by the East Garden was including the social space's expansion to the river and a competition among social space, water and urban streets .

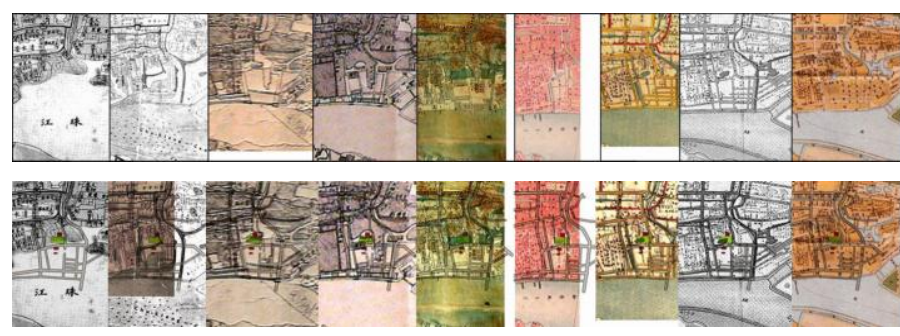

Figure 4. The historical maps compared with the past and the present

\section{THE SOCIAL SPACE AND THE RIVER}

\section{A. The Social Space's Expansion to the River}

Firstly the most important is the river. The East Garden was born because of the river. Then how the river changed? Pearl river is the mother river of Guangzhou. Many stories was launched along the Pearl river. These old stories told us, if the less river had not been closed off or filled in, it is possible that not only the Pearl river was left to be the important facade of Guangzhou. The body of water in chromatographic analysis of the historical maps tell that, under influence of water being filled in and social space's expanding together, the water body continued drawing back, and the area of Pearl river continued decreasing, and much water body changed from natural line type to manmade one.

In the map of 1900, the area of East Garden was still in the Pearl river, outside the south wall, near the East moat. From north to south , there was Yu Dai moat, Qing Shui moat, and the Pearl river. This situation continued to 1907. At that time, Until then, rivers had not been changed to roads yet, and street expanded from Qing Shui moat to Pearl river, and there was the East Gateway defense which is used to be the name of a street just beside, near the East moat.

In 1907, the area was coming up to be land from north to south. In the west of the area, the remained of the Pearl river was a branch of it which connecting Qing Shui moat and the Pearl river and branched a stream to east. In the south of the area, new land was reclaimed from the river. Not as the street with fine texture rapidly extending from the west of the area to Pearl river, this blank space had not been retained until 1910 which means it was preserved as a whole function and there was not any force which could invade. Compared with 1900, in 1907, there was significant alteration that the Long Dam had been finished. The accomplishment of this dam owed to Zhang Zhidong's decision about building a dam for preventing flood waters and revitalizing the economy. It lead the prosperous from the West Gate to the east of the Long Dam. In the map of 1914, we can see that a dam from Shamian Island to Guang Jiu railway station, which was the widest road in temporal Guangzhou ,and the east of Long Dam was named as the East Dam. At that time, the area of this part had been an flourishing shopping center and public place of entertainment. Since then ,the interface of the Pearl river turned from natural to artificial.

In 1905, Li Zhun was promoted to be the Prefect of the waterborne forces and chose to build his office right here .Because near the Pearl river, the way coming in the Garden from the Pearl river could be rowing, which is reason of site selection.

In 1910, the building of the East Garden appeared on the map. It was on the brink of the river, possessing the beauty of moon, pavilions, trees, flowers and fruits, so that it came to be a famous garden. Li Zhun did not posses it for a long time. Next year, after the Revolution of 1911, the East Garden was seized by government. We presume that the walls around the garden had been retained. From 1910 the year the garden built to 1932, there had been a straightforward moat which connecting the Pearl river with the pond in garden, and the pond kept the same size as primary. It can be said that water is the dominant factor of shaping space by the East Garden.

Till to 1937,most of the water was being up with silt, cut from the Pearl river, and the pond in garden was isolated.

We study several historical water system maps, as shown in the following pictures (Fig.5). The lower ones are superimposed by the space information including streets in 2012 and the area of East Garden. Then comparing with the past and the present, we can find out the result of the competition with social space and urban water as the following content.

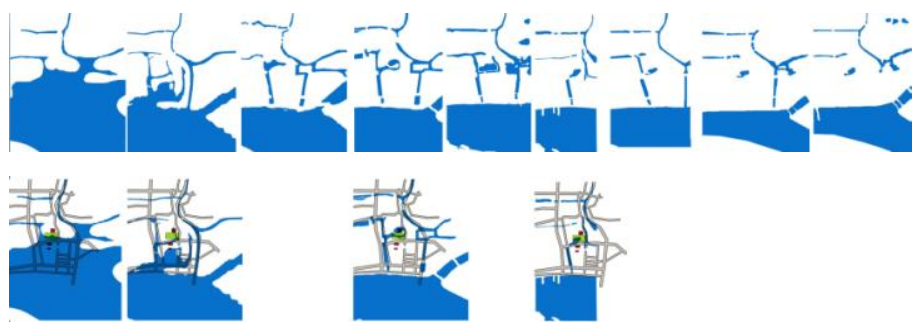

Figure 5. Historical water system compared with the past and the present

\section{B. Preliminary Summary}

Firstly, the maps indicate that urban public space extended facing to the Pearl river. Associated with the slender body of water extending to river and the retreat of the natural interface of the Pearl river, the land of city expanded. The power of river was driven to a corner which was the pond in garden and Dong Hao moat cut from it. Finally, the pond was filled into a terminal, and the Dong Hao moat filled into road. Even the young people living here are curious why there are these names, such as East Garden road, Zhan Pond road, River Security street. And they can nor believe that these road had ever been under the river, or you can see the river when open the front door of the garden, if they never see the historical maps. Because no garden, no pond, of course no river in the area, now. Anyway, the maps for this garden's area told us instead of the East garden that 
this garden was opening to the Pearl river, as a private garden, and due to the land extending to the river, as a square for citizen public activity, like revolutionary ones.

Moreover, the maps indicate that the space for the onrushing citizen public activity could get along well with the living zone for the citizens' daily life. Open blank and compact texture was the difference between urban public space and citizen's daily life zone. However they just coexist with each other, as an old man who lives nearby said that whatever assembly happened in the East garden ,never interfere they with other childre swimming in the East Hao moat.

\section{SOCIAL SPACE, WATER AND URBAN STREETS}

\section{A. A Competition Among social Space, Water and Urban Streets}

The East garden, as an arena of many kinds of forces, directly described how the streets are built up.

Two years ago ,before the cover of the Dong Hao moat has been removed, people don't understand why the viaduct and Yue Xiu Nan road which along with are both curving, compared to the Zhan Tang road and East Dam two or three road's straight. Look back to the map of 1907, we can find out there was similar line type like the viaduct and Yue Xiu Nan road have, but they were water body ,such as penstock or river. Put historical maps and present situation together, we have ample reason to believe that the streets in this area almost came from those semi-natural and semi-artificial water system. In 2012, the viaduct and Yue Xiu Nan road are just on the place of the Dong Hao moat and a stream left in the land because the Pearl river retreat in the map of 1907. However, the straight line less than $200 \mathrm{~m}$ below the East Garden, in the map of 1912, exactly was the East Dam Road planned by Zhang Zhidong, which is only one and first one road open to traffic in Guangzhou before the Revolution 1911. The Zhan Tang road in 2012, was a artificial stream connecting the Qing Shui moat and the Pearl river.

In view of these, the arc or bending of the streets, were not drawn by designer like the Arts \& Crafts because that a good idea suddenly occurred to him, but near the dominant river, the path of fluid flowing shaped by time and site together. On the other hand, the straight of the streets, were often the line drawn by penner on map. Some of them on land, and some came to be the boundary of water and land. So that, in this competition for space, the participants were not only social space and city water, but also streets, which sometime showed up as result.

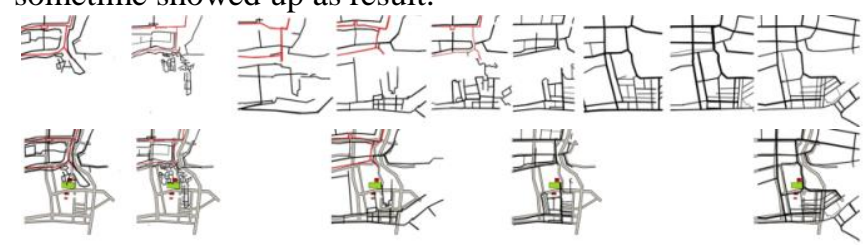

Figure 6. The historical street system maps compared with the past and the present, edited by writer

We study several historical streets maps, as shown in the following pictures (Fig.6). The lower ones are superimposed by the space information including streets in 2012 and the area of East Garden. Then comparing with the past and the present, we can find out the result of the competition among social space, water and urban streets as the following content.

\section{B. Preliminary Summary}

Firstly, city life extended from north to south, and the line type of streets carried on the gene of the social events happened on land. The straightness of the streets was because of the precise planning inside of the walls, or besides of the walls. The wideness was because of the walls pushed down all. The fine-grained suddenly was due to the streets' scale developing freely of daily life for the everyman who live outside the walls. The walls pushed down and the road widen, brought convenience to go from the city center to the East Garden, which was exactly the reason why the garden could be the place selected to hold a large assembly.

Secondly, the social events happening, 'threatened' road network expanding from the Pearl river to north neatly, stopped before the East Garden. In 1907, the East Dam was $200 \mathrm{~m}$ south of the East Garden, and the Guang Jiu railway station was $300 \mathrm{~m}$ southeast of the garden, and the Da Sha Tou wharf which used as airport on river was $500 \mathrm{~m}$ southeast of the garden. All of those factors were beneficial to this open space around the garden. Many wealthy businessmen quickly bought much riverside land to develop. So that the land reclaimed from the river, were divided neatly by large chunks, without other topographic effects, and entertainment business was prosperous at one time .

Thirdly, even facing the 'attack' from the north and south streets, the East Garden had not been penetrated yet before 1937. That means the garden without a precise owner as open space where many social events happened, had more power than solid street did. What's important to note is that after 1926, the East Garden had been burnt down to a front gate, but those assemblies were hold still frequently. No matter how the economic and urban development needed more space, the appeal from civic space would be satisfied firstly.

The last point is that the main transportation changed from water to land. In the map of 1928 and 1932, waterway was taken place by streets. The water transportation gradually declined and the vehicle changed from boat to bus or car ,or even plane. Surely, the reason including the Canton-Kowloon railway station and Da Sha Tou pier. That convenience was the reason why the East Garden selected as headquarter of the Canton-Kowloon United Strike ,at the same time.

\section{SUMMARY}

After the text edit has been completed, the paper is ready for the template. Duplicate the template file by using the Save As command, and use the naming convention prescribed by your conference for the name of your paper. In this newly created file, highlight all of the contents and import your prepared text file. You are now ready to style your paper; use the scroll down window on the left of the MS Word Formatting toolbar. 
In summary, the East Garden, such solid space as a building, a street in a city, was a kind of multiple complex. It narrate about social space with rich layers. Every sound representing different actor came to be a mixed chorus, and there was always a competition among several participators. During reading, we can discover the real characteristic of the narrater. The East Garden, at first came up as a private garden, but after years of narrative, it let us vividly believe that it was exist as "city square". The narrative reflect some space construction, the emotional tangle in the use of space, the different traction forces, the gravitational pull of city and society, and some historical relationship in structurally or non-structurally.

\section{REFERENCES}

[1] The First Historical Archives of China, Guangzhou Archives Bureau and Government of Guangzhou Yuexiu District: Yue Dong Shengcheng Tu of 1900,Selected Historical Maps of Guangzhou, Encyclopedia of China Publishing House, China(2003), pp.80.

[2] The First Historical Archives of China, Guangzhou Archives Bureau and Government of Guangzhou Yuexiu District: Guangdong Shengcheng Neiwai Quan Tu of 1907,Selected Historical Maps of Guangzhou, Encyclopedia of China Publishing House, China(2003), pp. 84 .

[3] The First Historical Archives of China, Guangzhou Archives Bureau and Government of Guangzhou Yuexiu District: Guangzhou
Shengcheng Tu of 1910,Selected Historical Maps of Guangzhou, Encyclopedia of China Publishing House, China(2003), pp.90.

[4] The First Historical Archives of China, Guangzhou Archives Bureau and Government of Guangzhou Yuexiu District: Guangzhou Cheng Tu of 1917,Selected Historical Maps of Guangzhou, Encyclopedia of China Publishing House, China(2003), pp.91.

[5] The First Historical Archives of China, Guangzhou Archives Bureau and Government of Guangzhou Yuexiu District: Guangzhou Shi Tu of 1918,Selected Historical Maps of Guangzhou, Encyclopedia of China Publishing House, China(2003), pp.95.

[6] The First Historical Archives of China, Guangzhou Archives Bureau and Government of Guangzhou Yuexiu District: Guangzhou Shi Tu of 1928, Selected Historical Maps of Guangzhou, Encyclopedia of China Publishing House, China(2003), pp.98.

[7] The First Historical Archives of China, Guangzhou Archives Bureau and Government of Guangzhou Yuexiu District: Guangzhou Shi Malu Luxian Tu of 1932, Selected Historical Maps of Guangzhou, Encyclopedia of China Publishing House, China(2003),pp.102.

[8] The First Historical Archives of China, Guangzhou Archives Bureau and Government of Guangzhou Yuexiu District: Guangzhou Shi Zuixin Malu Quantu of 1937, Selected Historical Maps of Guangzhou, Encyclopedia of China Publishing House, China(2003), pp.106.

[9] The First Historical Archives of China, Guangzhou Archives Bureau and Government of Guangzhou Yuexiu District: Xin Guangzhou Shi Jiedao Xiangtu of 1949, Selected Historical Maps of Guangzhou, Encyclopedia of China Publishing House, China(2003), pp.122.

[10] Information on http://www.zggzds.gov.cn 